Article

\title{
Decolonizing Methodologies, Situated Resilience, and Country: Insights from Tayal Country, Taiwan
}

\author{
Yayut Yishiuan Chen
}

Master's Program of Land Policy and Environmental Planning for Indigenous Peoples, College of Social Sciences, National Chengchi University, Taipei 11605, Taiwan; yayutchen@gmail.com or yayut@g.nccu.edu.tw; Tel.: +886-02-2939-3091 (ext. 50551)

Received: 30 September 2020; Accepted: 17 November 2020; Published: 23 November 2020

\begin{abstract}
This paper addresses the methodological challenges of working with Indigenous peoples in the Anthropocene. Drawing from the author's geographical fieldwork with Tayal people, one of sixteen nationally recognized Indigenous groups in Taiwan, it argues that ontological shift is required in the dominant ways of thinking about resilience research. After reviewing a well-adopted Australian custom called 'Acknowledgement of Country', the paper addresses the concept of Indigenizing methodology and mobilizing the concepts of 'Country' and 'situated resilience' in Tayal settings. Finally, the paper proposes methodological principles for better engaging Indigenous knowledge in a more-than-human world on an ethical and constructive basis, as well as its implications for resilience research.
\end{abstract}

Keywords: decolonizing methodologies; Acknowledgement of Country; Taiwan; Indigenous geographies; Tayal people; situated resilience

\section{Introduction}

With rising awareness of climate change, there are increasing scholarly and governmental focuses on Indigenous and local communities' knowledges as sources for resilience [1-3]. While this long-overdue recognition is important, academic and institutional players in climate change adaptation and policy research too easily assume privilege and discretion belongs only to them and is not available to marginalized Indigenous groups. It is, perhaps, unsurprising that methodological approaches to reflect and respond to ethical engagement with Indigenous peoples are not well developed in scholarly research [4]. How to ethically involve Indigenous peoples, and even acknowledge Indigenous peoples' leadership in research demands more actions from governments and academia. Much more careful, respectful and humble attention is required if academic, policy and development practice is to address the significant capacity deficits [5] in academic and institutional settings. This paper is based on geographical and ethnographic research methods and personal experiences over the course of time as an academic while I engage with literatures in an Indigenous context (for interviewees list please see the Appendix A). Research methods adopted include participatory observation, in-depth interview and mental mapping. Drawing on geographical fieldwork with Indigenous Tayal people in northern Taiwan, this paper argues that understanding human-environmental relationships, natural disaster, adaptive responses and societal resilience through engagement with Tayal ontologies provides valuable guidance in developing decolonizing methodologies for climate change adaptation research and policy development. The Tayal people are an Indigenous group with a population of 92,306 as of April 2020 [6] who dwell in mountainous area, northern Taiwan (the total Taiwanese population is $23,829,964$ as of October 2020). They are one of the sixteen Indigenous groups recognized by the national government in the Republic of China (ROC) in Taiwan. This paper reflects on engagement with Tayal people, and it mobilizes three key concepts-Country, ontological pluralism and situated 
resilience-as a foundation for responding to the need to think outside the conventional frameworks of already-colonized thinking that privileges state, academic and global institutional thinking over local and Indigenous understandings of current circumstances. Through critical reflections, this paper aims to provide methodological principles that will better engage Indigenous peoples in resilience research and policy.

\subsection{The Concept 'Country'}

As pervious research shows in the Tayal settings, governing water resources is not about exercising sole ownership over a natural resource, but about governing human and non-human agencies in a more-than-human world [7]. In this paper, I explore Tayal ontological understandings of their place in the world, and its implications for resilience research. Further, this paper proposes methodological principles for engaging Indigenous knowledge in a more-than human world on an ethical and constructive basis.

The idea of 'Country' as a way of characterizing the relationships between Indigenous groups and their territories and the wider world is a central concept in this paper. The concept is drawn from Aboriginal Australians' usage of an English term. In Aboriginal Australian settings, the term Country implies a very different meaning from general English usage to refer to either a nation-state or to a rural setting. Country is "an Aboriginal English term that encompasses particular areas as they co-become-shape and enable each other-in human and more-than-human relations of response and responsibility" (p. 24) [8]. The concept comprises complex ideas about relationships and connections. It simultaneously encompasses "territorial affiliation, a social identification and cosmological orientation" (p. 370) [9]. Learnt from her working experience with Australian Aboriginal peoples, Rose [10] develops the concept of Country as a "nourishing terrain". In her words she notes: "Country is a place that gives and receives life. Not just imagined or represented, it is lived in and lived with" (p. 7). To further elaborate, Rose [10] explains that Australian Aboriginal peoples do not perceive their Country as a nature/culture dualism. On the contrary, "Country in Aboriginal English is not only a common noun but also a proper noun. People talk about country in the same way that they would talk about a person: they speak to country, sing to country, visit country, worry about country, feel sorry for country, and long for country "(p. 7).

\subsection{Ontological Pluralism}

Recognizing 'Country' and setting it is central to understanding the challenges of resilience science. It implies a centrality for a more-than-human ontology. It demands de-privileging any human-centric understanding and practices of natural resource management and opens up a space to recognizing plural and non-linear relationships between people and environment. 'Country' encompasses human and non-human agencies in a more-than-human world [11]. If one's starting point is acceptance that western science has a self-evident advantage over all other forms of knowledge, this requires quite a fundamental rethinking of humans' place in the world. Acknowledging Aboriginal Australians' connections to and custodianship of their Country ultimately requires acceptance of the need to recognize ontological pluralist understandings of nature and has implications for how to pursue sustainability.

Ontology, understood as a branch of metaphysics, is the science of being, embracing such issues as the nature of existence and the categorical structure of reality [12]. That is, ontology is about being, existence and knowing in the Cosmos. Ontology is the foundation of how humans know themselves and the Cosmos. While ontology is clearly defined in many philosophy and social theory texts $[12,13]$, the implication for understanding and for claiming its power is rarely understood in the common discourses of climate change and disaster management. Howitt and Suchet-Pearson [14] advocate that ontological pluralism should be recognized in contested cultural landscapes [14,15]. They [14] argue "academic discourse typically represents its knowledge as detached, objective and universal". They propose engaging with "alternative ontologies-diverse ways of knowing, 
being-in-place and related to complex, often contested cultural landscapes at various scales" (p. 557) as their alternative to relying on an inadequate singular, homogenous and dominant ontological discourse.

For Howitt and Suchet-Pearson, ontological pluralism goes beyond Euro-centric philosophies as the foundation for being-in or knowing the world. They argue that diverse ways of knowing the world are extremely important for reframing dominant forms of natural resource governance. Culture shapes the way people know the world, and the way people locate themselves in relationship with the Cosmos [16-18]. To decenter the dominant human-centric ontology, which assumes a hierarchical order between human/non-human, Suchet-Pearson and her research partners raise the idea of a 'relational ontology" $[16,19]$. They elaborate it as "a relational ontology of connection means understanding all beings and things as inherently connected. Neither one's identity, actions or ethics can be understood in isolation from other research partners, family members, other people, or the natural world. Rather, humans, animals, plants, winds, rocks, spirits, songs, sunsets and water, indeed all things, are connected together in a web of kinship and responsibility" (p. 1076) [19].

\subsection{Situated Resilience}

In climate change adaption discourses, resilience has a long history [20-26]. I advocate the notion of 'situated resilience' in this paper. It emphasizes the specific temporal-spatial context in which the concept and practice of resilience are generated, defined and exercised. It alters the conventional thinking that resilience strategies are universally applicable and propose that resilience strategies are responsible for and ethically engaging a specific temporal-spatial context. The notion of 'situated resilience' requires a careful tackling on ontological politics. It is useful to visit the discussion on relational ontology proposed by the work of the Bawaka Collective (e.g., Lloyd K [19] and Bawaka collectives $[16,27])$. The relational ontology not only de-centers human-centric privilege in the creation and evaluation of knowledge, but also profoundly asserts the need to recognize that multiplicity resides within the concept of ontology. This in turn implies that the concepts mobilized to engage with relationality on more-than-human systems must also be carefully contextualized and situated.

The deployment of resilience is neither self-evident nor universally applicable and there are multiple versions of resilience being mobilized in contemporary discourses [28]. Scholars reflect on Indigenous ontologies to argue the importance of situating resilience in a specific temporal-spatial context. Fisher [29] reviews how 'resilience' has been deployed and applied in fundamentally different ways in two research-focused settings. She argues that the notion of resilience is not a modern invention, and that in Aotearoa/New Zealand, Maori ontologies influence how resilience is enacted and that "entanglements that arise when worlds collide" (p. 34) provide a catalyst for change as Maori "assert their rights to different ways of knowing and being and as the differentiated effects of resilience interventions are made apparent" (p. 35).

The Bawaka Collective [8] maintain that "ontological politics must be sited" (p. 24), and that the ontological politics of resilience not only can be learned from place, more importantly, it is of place. They maintain that the resilience demonstrated by Indigenous peoples in their more-than-human settings is always to be understood as situated. There is a deep sense of place in this notion of resilience. From this perspective, there is no universalized, abstract notion of resilience because resilience is inherently situated in a relational web of connections across time and space. They also demonstrate for Indigenous Yolngu people in Australia, weather is not a 'natural' phenomena that is separated from 'culture' and call for an "embodied, emotional, affective experience" (p. 297) on weather and climate [30]. The importance of local scale practice has been widely acknowledged in resilience science [26,31].

So, resilience strategies are not, and cannot be universally applicable. On the contrary, it is important to acknowledge that engaging with the ontological politics of resilience requires engagements with those whose situation has given rise to the resilience (or lack of resilience) that is at issue. In other words, given that recognition of ontological pluralism demands the recognition that situated resilience of Indigenous groups is embedded in the geographical, historical, cultural and political context in which 
people are entangled, researchers, policy-makers and advocates alike must develop methodological approaches that respond respectfully, humbly and patiently to context.

\section{Acknowledgement of Country-Acknowledging Context}

\subsection{Acknowledging Indigenous Context}

As Howitt [32] recognizes, in Australian Indigenous settings, a 'Welcome to Country' is a custom among many Aboriginal groups to assess the bona fides of visitors and ensure their safe passage in Country. That custom is now extended to include Traditional Owners giving a welcome to non-Indigenous groups at the start of a speech or an event. Arising from the growth of the reconciliation process there is also an increasingly common use of an 'Acknowledgement of Country', which can be used by anyone-Indigenous and non-Indigenous-to acknowledge the Traditional Owners of the land at the start of a speech or event [33]. Acknowledgment rituals are structured as affirming recognition of the entitlement and belonging of Indigenous persons or groups to a place, typically by an outsider. While the Acknowledgment is a matter of appreciation, or a declaration made to ensure validity, the Welcome has a classic host-guest structure. A host is normally someone who has an entitlement or belonging within a domain to which the guest is admitted. The host is to be respected but is also morally bound to extend hospitality to the guests. An Acknowledgment may be made by someone without direct address to those understood to be acknowledged, and without reciprocation; a Welcome frames both parties as participants of the event (Merlan [34] p. 298). There is no doubt that some elements of Welcome (such as smoking and dance) have long been in use among groups of Indigenous Australians, but most Australians realize that both ritual forms have become part of public protocol in the recent past. The two rituals started coming into public use during the 1990s, as a form of recognition during the reconciliation decade (see Merlan [34] pp. 299-302).

As a Taiwanese visitor to Australia, the Acknowledgement of Country for me, is very much about acknowledging connections-the connections that encompass people-to-environment, people-to-people and people-to-Cosmos relations [35,36]. This paper addresses the methodological challenges of working with Indigenous peoples by starting with a positionality of recognizing and acknowledging Tayal custodianship of Country. Therefore, I would like to acknowledge Tayal people and their Country and offer my appreciation of the opportunity to work with and learn from them, and acknowledge the entitlement that accompanies Indigenous Tayal peoples' belonging to place and aim to emplace the following discussion in the specific context where knowledge are generated.

\subsection{Mobilizing Resilience in Tayal 'Country'}

Applying the Australian Aboriginal notion of Country in the Taiwanese setting, Hsu, Howitt and Chi [9] felt there was an opportunity to "inspire a novel and constructive approach to questions regarding Indigenous experiences of disaster relief and reconstruction in Taiwan" (p. 371). They go on to argue that First Nations' social, political and environmental histories shape their resilience and capacity to recover from disruption. In disaster recovery, they say, the idea of Country helps to understand how effective and culturally appropriate recovery activity will "consider the social dimensions of community (people-people), the cultural and spiritual dimensions of identity and community (people-cosmos) and the socio-ecological dimensions of community well-being in terms of livelihood, history and values (people-environment)" (p. 374).

In Tayal domains, however, the complex histories of colonization, dispossession and displacement have produced a range of institutional arrangements that claim to exercise power over Tayal people, Tayal environments and Tayal lives [37]. Despite this, many aspects of Tayal spiritual life, self-determination and governance persist in relationships guided by the philosophy of Gaga [38] and the processes of managing Tayal resources for survival $[39,40]$ and shape the ways in which Tayal communities respond to changing circumstances in their lives. Developing a research methodology to understand and support local resilience has required significant entangling with Tayal people, language, culture and 
history and developing a strong sense of belonging within Tayal communities and places. While some elements of my own experience have been intensely personal, there are many aspects of the work that offer methodological lessons with wider application. The work of listening to and learning from Tayal mentors, rather than assuming that Tayal experience and understanding is simply data to be collected and analyzed using already-colonizing tools, for example, has required recognition of the ontological foundation of their experiences of resisting, responding and asserting their custodianship of their Country despite Settler State's consistent ignorance, hostility and denial that Tayal autonomy could pre-date and persist beyond the creation of the state. In particular, in the Tayal context, it has been through engaging with stories of connection, place and belonging and lmuhuw (migration history chanting) that I have come to understand that the notions of climate change and disaster management that have been normalized in mainstream international and domestic discourse are themselves colonizing in their impact and erase the insights and opportunities created within Tayal-centric discourses (see also [41,42] for parallel examples elsewhere in Taiwan).

That is, understanding and supporting Tayal resilience in Tayal Country requires a methodology that recognizes the ontological politics of resilience, acknowledges the ontological priority of Country and context in Tayal settings, and engages with resilience as situated rather than as some sort of universal abstraction disconnected from people, place and context.

\section{Decolonizing and Indigenizing Methodologies-Towards a Tayal-Centric Framing}

\subsection{Framing Methodological Challenges}

Linda Tuhiwai Smith's landmark book Decolonizing methodologies: Research and Indigenous peoples [4] profoundly affected Indigenous studies. The fashion of postcolonialism, in Smith's words, has become a strategy for re-inscribing or re-authorizing the privileges of non-Indigenous academics because the field of 'post-colonial' discourse "has been defined in ways which can still leave out Indigenous peoples, our ways of knowing and our current concerns" (p. 25). Referring to Smith's words, Sikes [43] argues that the applicability and meaning of the 'post' prefix, and particularly when it is hyphenated, is problematic. Not only does 'post' suggest a temporal linearity and a definite in-the-pastness which some (ex)colonized peoples may not experience or perceive, it perpetuates the 'othering' and emphasizes oppositions and binaries. A central task of projects of decolonization is, and should be, to go beyond such reductive polarizations (pp. 350-351).

The publication Decolonizing methodologies marked an important milestone for research with Indigenous peoples. However, it also requires careful consideration when responding to this framework and adapting it for use in different Indigenous settings. As noted by Smith herself [4], even the term 'Indigenous' is problematic in that it appears to collectivize many distinct populations whose experiences under colonialism and imperialism have been vastly different (p. 6). Rather than distinguishing and binarizing Indigenous people versus settlers, Mlcek [44] argues that decolonizing methodologies are about making the connections. The storytelling process both resists and intervenes to cocoon the individual in a state of protective and strengthening sustainability. The telling of personal stories is a powerful way to talk about life experiences within a socio-cultural context, especially when they relate to being "on the borders" [44] (pp. 85, 88). Decolonizing methodologies challenges researchers to think deeply of their own colonial and cultural contexts and provokes a nascent research paradigm embedded in specific cultural settings. However, Leslie [45] found that the label 'decolonizing' is not suitable in her own Kamilaroi cultural context. To avoid conflating a specific Indigenous context into a colonized/de-colonizing binary, through reflective thinking in Kamilaroi language, Leslie [45] developed her own Wingangay methodology. The root 'winanga' is translated as 'hear' and the verb for winanga, Winangay goes beyond just hearing. In Leslie's Kamilaroi culture, like many oral cultures, "the ear is seen as the instrument or seat of intelligence and perception, therefore winangay goes beyond just hearing." (p. 203). This approach shifts the relationship between the privileged researcher and 
their research subjects away from one of colonizing knowledge whereby knowledge is something to be possessed by the researcher and reframes the research relationship in very different ways.

\subsection{Tayal People's Ontological Understanding of 'Country'}

The above issues prompted me to think deeply about how to frame resilience studies. Decolonizing methodologies introduced me to the idea of framing a research methodology with Indigenous peoples, but it also reminded me that 'Indigenous' is a problematic label, which might conflate diverse experiences of colonized peoples. Indigenous research methodologies should be embedded in a specific context, rather than just adopting a generic decolonizing methodological paradigm without being aware of the context. Thus, I frame this paper as radical contextualism, an idea recently introduced to geography [36]. Extending from this methodological framing here, I address the Tayal people's ontological understanding of 'Country'.

In April 2012, a surprising incident occurred on Tayal Country. Police caught a Tayal person from Smangus community 'unlawfully' logging cypress in the traditional territories, which had been categorized as State forest, of another Tayal community: Pyanan community. On one hand, the Taiwanese State argued the man's action was illegal because according to the ROC legislation, all timber in State-owned forest are State property. Hence, the accused man had stolen State property. On the other hand, Tayal people felt the man's action in this case was customarily illegal because the suspect had violated Tayal Gaga (the Law in Tayal ontology). In Tayal Gaga, violating the Gaga (Law) of boundaries is the most severe transgression. Tayal people have very rigid Gaga (Law) of boundaries regarding rivers, hunting grounds and cultivating fields. Respecting the boundary and never moving across it without permission is fundamental in Tayal ontology. This incident especially stirred Tayal people in the Pyanan community to anger because it was a Tayal person who had encroached their territory, not an outsider. In order to settle the anger and amend the relationship between the communities, the two communities decided to hold a Sbalay (Reconciliation) ceremony in Quri Sqabu, one of the vital bifurcated places during Tayal people's epic migration [46]. They chose Quri Sqabu as the ceremony venue because it was where Tayal ancestors had agreed to ally with each other before they separated into different watersheds and built their communities. In their oral history lmuhuw chanting, when a Tayal ancestor Kbuta led Tayal people migrated to Quri Sqabu, he said to his people they would separate from here, and exhorted his people to follow rivers and build their communities (see also [7]):

You shall not turn your back on each other. When boys turn mature, be prudential of blood relation [to avoid incest taboos]. If you hear of a well-educated girl, you shall ask elders to propose in proper ways. Then your children shall thrive as well as bamboo shoots. (Zheng [46] ch.4 p.9 (my translation))

The Pyanan community and the Smangus community performed a Sbalay (Reconciliation) ceremony not only for amending relations, but also for proclaiming their sovereignty over their Country and re-strengthening the Tayal alliance. Thus, this ceremony was also a Phaban (Alliance) ceremony (see: [47]). The Sbalay (Reconciliation) ceremony was held on 4 May 2012 at Quri Sqabu near the Pyanan community. I arrived at the Pyanan community on 3 May 2012. I was visiting the Pyanan community as a postgraduate student and was about to commence my fieldwork in the community. That night, elders from Tayal Country gathered together at the Pyanan Presbyterian Church. A map was drawn to denote the Tayal Country (Figure 1). This map was used in the Sbalay (Reconciliation)/Phaban (Alliance) ceremony the next day (Figure 2).

This map is titled 'the traditional territory of Tayal people' (the green words on the top). This map represents Tayal Country. Each river in Tayal Country is drawn in blue lines with the Tayal name labelled in blue and the Mandarin name labelled in purple. Each river represents a watershed and a clan of Tayal people. For instance, llyung Tmail is the name of river Tmali and the name of the clan living inside the watershed of river Tmali. The location of Quri 
Sqabu is marked in the red circle, and the presented point the elder is pointing at is the sacred mountain Papak waqa. The small figure in the right bottom corner indicates the area of Tayal Country in Taiwan (the red bordered area) and indicates other Indigenous peoples in the island (the yellow bordered area). (Photo taken on 3 May 2012 at the Pyanan Presbyterian Church. Credit: Huei-Chung Hsiao. Reproduced with permission)

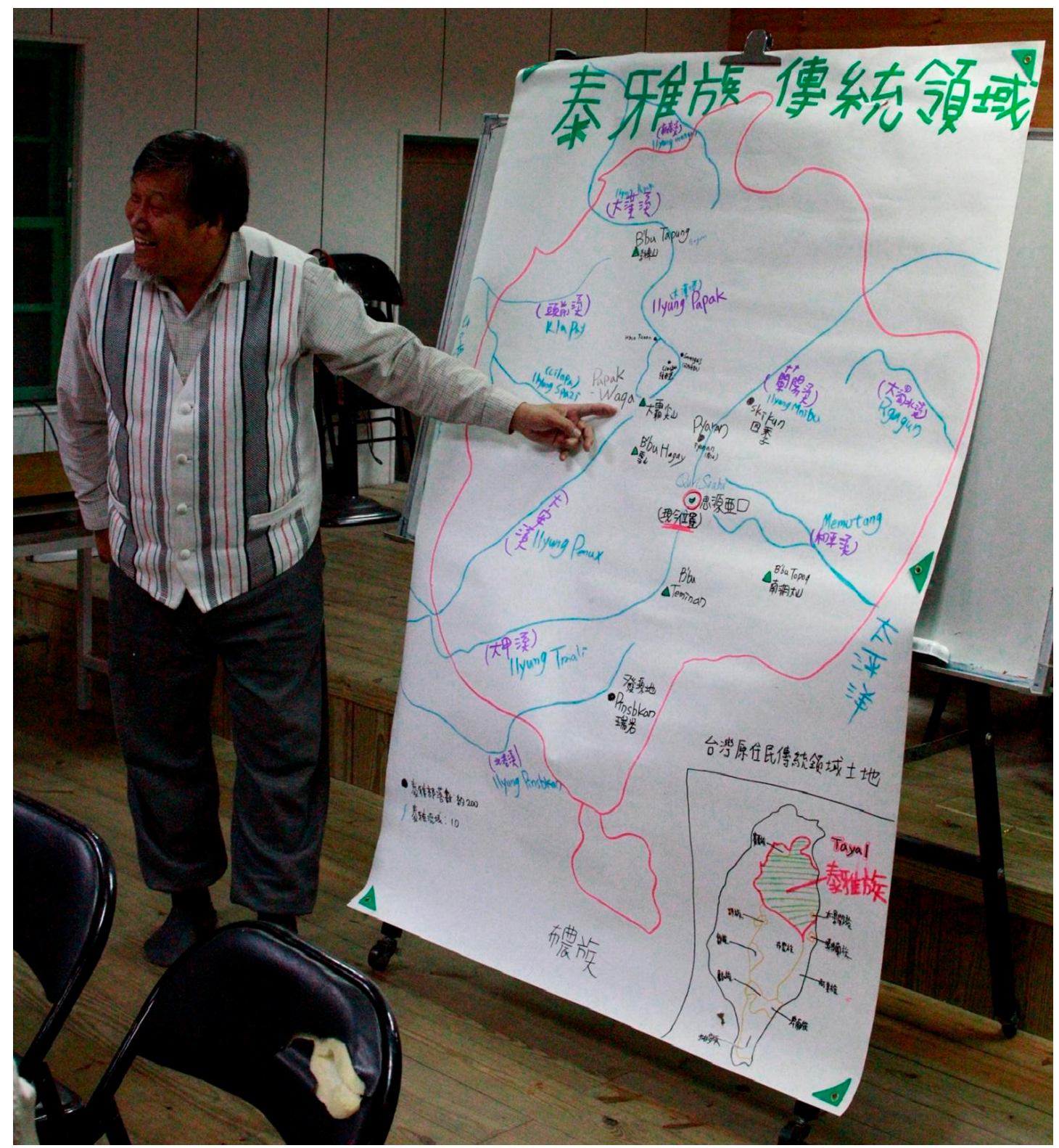

Figure 1. A map of Tayal County prepared for the Sbalay (Reconciliation)/Phaban (Alliance) ceremony. 


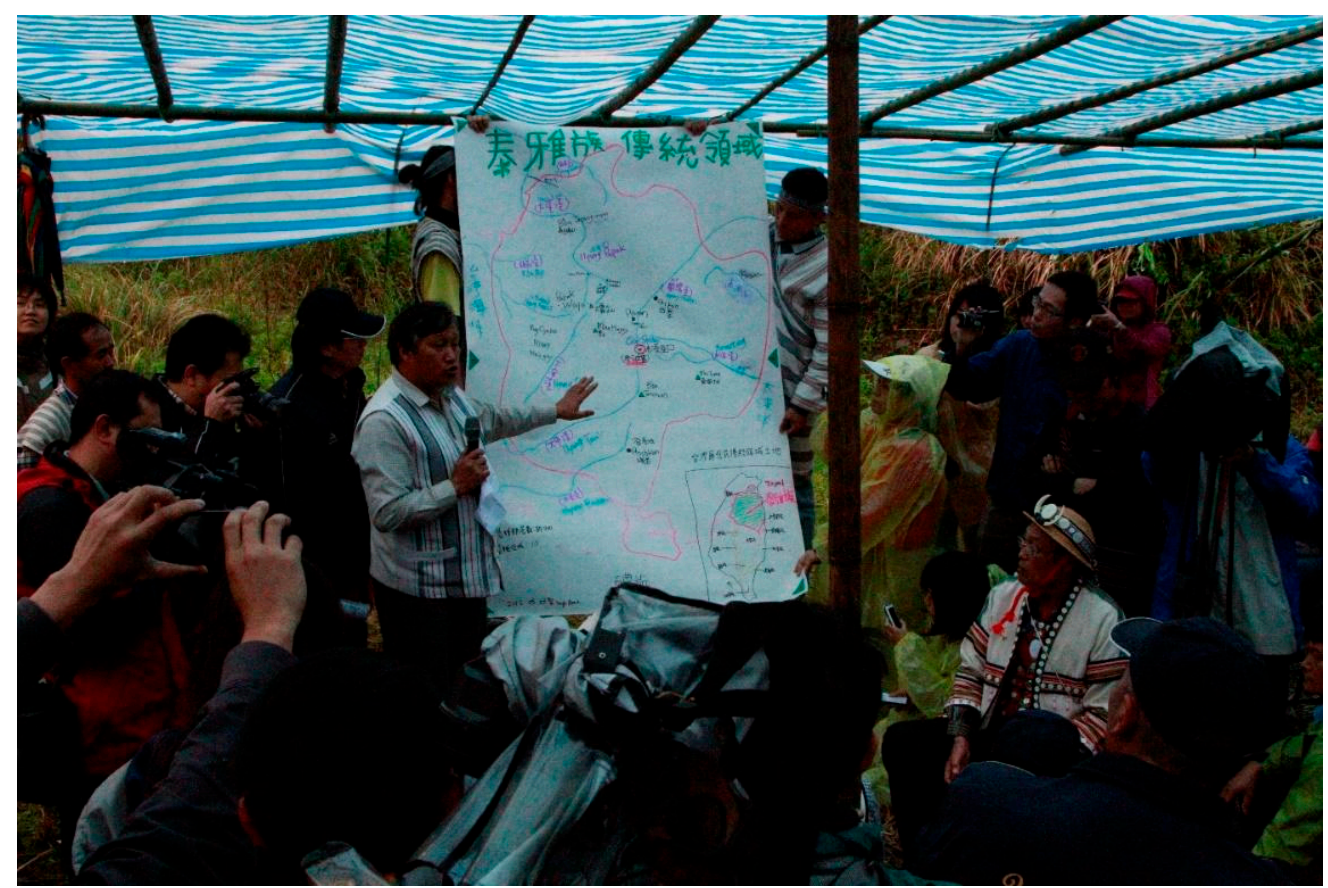

Figure 2. The Sbalay (Reconciliation)/Phaban (Alliance) ceremony. (Photo taken on 4 May 2012 at Quri Sqabu. Credit: Huei-Chung Hsiao. Reproduced with permission).

The ceremony began with an introduction and included following programs:

- $\quad$ Pramu minqyanux (Sacrifice and purification): Killing a pig as the sacrifice

- Smrhuw qyunam Tayal (Proclaiming Tayal traditional territory)

- $\quad$ Lmuhuw msgail qwas (Migration history chanting)

- Pinhaban qyunan Tayal (Alliance): each Tayal clan sent a representative to proclaim the alliance by dipping some pig blood on the map.

- Pmumu pinhaban ke (Vow to ally)

- Qwas sinrhgan ke (Exhortation from elders)

- Pzimuw pngsa' (Prayer for thanksgiving)

- Mqwas sinramat (Tayal hymns)

The Sbalay (Reconciliation)/Phaban (Alliance) ceremony profoundly shaped my methodological framing. I can still recall the memory vividly. It altered my understanding of 'Taiwan'. I was born and raised in a Han family, the descendants of Chinese settlers. Having faith in the State for me was something normalized in my daily life. Yet, in that ceremony, Tayal people requested apologies from the State for sabotaging Tayal forest regulations and rejected State policy that they saw as fallacious [48]. In the ceremony the territory was presented, the vow was made, and the alliance was strengthened. 'It was and always will be their Country' I thought. I had a strong feeling that they were/are governing their Country in Tayal ways. Given the suspect has been arrested by the ROC police force, Tayal people decided to settle according to the Tayal Gaga (the Law). The reconciliation process in Tayal ontology is about re-connecting and strengthening ongoing relations. There was a strong connection of time and space in that ceremony. Choosing where the Tayal ancestors had bifurcated during their epic migration as the ceremony venue connected the past of Tayal people to their present, as well as connecting to an allied and reconciled future. Representatives from every watershed vowed to work together in the program of alliance, connecting Tayal places across Country into a congregation. The notion of Tayal Country is more than a bounded area. Rather, it encompasses connections across time and space between Tayal people, place and Gaga. 
Attending the Sbalay (Reconciliation)/Phaban (Alliance) ceremony in 2012 altered my understanding of Tayal Country utterly. It made me realize Tayal people governed and continue to govern their Country in their own ways, despite persistent colonial interventions. Tayal people are always retaining and renewing their connections to their Country and each other. Tayal connections to Country are built on relations with rivers, mountain and people co-existing in the Country. In order to emplace this paper in the ways Tayal people see, think and do, it is important to explore the ways in which the Tayal-centric approach to questions of belonging, connection and Country. It also requires a profound rethinking of Indigenous peoples' connections to space, time and place.

\section{Recognizing Relational Webs in Tayal Country}

In the wake of transitional justice in the Taiwanese national polity see [38], recognizing the conceptual framework of ontological pluralism $[14,15]$ in Taiwanese contested cultural landscapes sets the ground for later discussion. Inspired by the Australian Aboriginal protocol of an 'Acknowledgement of Country', my research responds to the methodological challenges of contextualizing this paper in a specific-temporal-and-spatial scale and cultural-and-geographical-appropriate context.

Acknowledging Tayal people's custodianship of Country is the entry point to establishing that a Tayal ontology of place must inevitably shape research about Tayal places. In Taiwan, the complex histories of colonization failed to accommodate Tayal people and Tayal Country as already encompassed by Tayal ontology, law (Gaga) and responsibilities has seen much scholarly research framed in ways that privilege colonial and colonizing values. As Rose (1999) recognizes, even well-intentioned research risks being caught in the web she characterizes as "deep colonizing". Recent Indigenous and other scholarship in Australia [49], Aotearoa New Zealand [50] and North America [51] and more broadly in the emerging field of Indigenous geographies [52,53] offer timely and contextualized advice on how to reconceptualize research methodology in Indigenous settings. The challenge of radical contextualism, however, is to move beyond some sort of generic and abstracted Indigenous frame to the particularities of a specifically Tayal frame for this research.

In their work on "being-together-in-place", Johnson and Larsen [54] offer some valuable insights into the challenges of building a Tayal-centric methodology for this research, but their work does not refer to Tayal Country and culture. Rather it draws on work in New Zealand and North America. Similarly, the powerful insights of the Bawaka Country research collective [16,27] provide valuable guidance and suggestions, but is not Tayal-specific. The key challenge is to take the reader into the relational web of Tayal Country and its people, to move beyond acknowledgement and towards engagement.

I have sought to follow a path to Country that sits comfortably in and is able to be challenged and transformed by my Tayal guides, mentors and teachers. In other words, my methodology has developed as Tayal-centric-drawing on guidance and insights from wider scholarly debates about Decolonizing methodology and Indigenous geographies, but always coming home to Tayal Country, Tayal advisors for review, affirmation and approval. My personal journey has immersed me in Tayal social relations, taken me into my Tayal family, and held me accountable in Tayal customary discourses. This is a continuing journey, and one that I hope will allow me to nurture research that moves from being Tayal-centric to being Tayal controlled, governed and driven. But in explaining the Tayal-centric methods developed and applied in this research, let me first take the reader on some of my journey into that relation web of people, mountains and rivers in Tayal Country.

\subsection{Rivers, Mountains and Peoples: A Relational Web}

From January 2018 to February 2018, I intensively visited a Tayal pastor recently retired from the Presbyterian Church. Pastor Sangus is a pioneer and social activist from the 1980s. He is one of the people I have come to admire since I started working with Tayal people in 2009. I was lucky enough to interview him at some length. I wanted to interview him because of a figure he drew for another scholar's doctoral dissertation to explain the ontology of Tayal People (p. 157) [55]. As elaborated in 
Chen, Suchet-Pearson and Howitt [7], Tayal people migrated from central Taiwan to northern Taiwan and continuously built communities along rivers [7].

Figure 3, a map recorded by Japanese anthropologists Utsurikawa, Mabuchi and Miyamoto [56], gives a sense of geography of Tayal people's migration pathway. The red square shows the area discussed in this paper. The mountain Papak Waqa plays a paramount role in the Tayal people's creation. The actual geography of Papak Waqa is a matter of dispute among various clans of Tayal people, while generally in the research area people name it as the Dabajian Mountain (Mandarin: 大霸尖山; Elevation: 3490 m; Coordinate: $24^{\circ} 27^{\prime} 58^{\prime \prime} \mathrm{N} 121^{\circ} 15^{\prime} 29^{\prime \prime}$ E). Papak means 'ear' in Tayal language and waqa means 'split'. Mountain Papak Waqa might be named after the shape of its peak. It looks like an ear-shaped stone came out from a split (Provisional Commission for the Investigation if Taiwanese Old Customs 1996 (1915): 18).

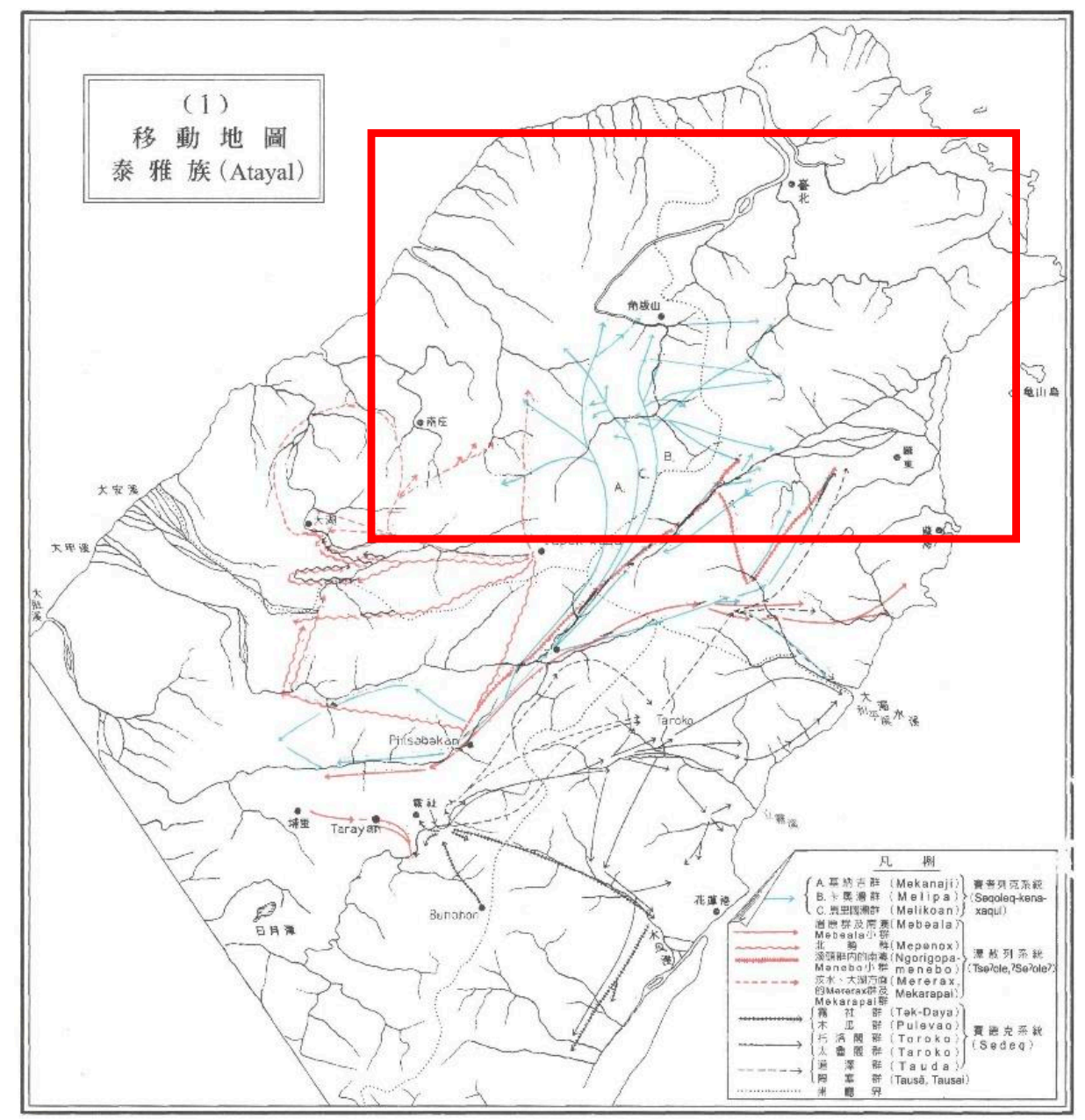

Figure 3. Tayal People's migration pathway recorded by Japanese anthropologist (Utsurikawa, Mabuchi and Miyamoto [56]) (Reproduced with permission for non-profit use).

The various versions of Tayal creation myths share common features. Here I present one to demonstrate the role of Papak Waqa (sacred mountain):

In the old time, there was one huge rock on Papak Waqa (sacred mountain) which suddenly split and one man and one woman walked from it (...) gradually their descendants multiplied and spread out. One day, a deluge took place, and only the peak of Papak Waqa (sacred mountain) was not drowned. All the people rushed to the peak. After discussion, the public agreed that someone must have violated taboos and that was the reason for the deluge. Hence, compensation was demanded. The public threw a dog into the water, 
but nothing happened. Then the public threw an elder into the water, but still nothing happened. The public confirmed there must have been offenders among them. They did a thorough investigation and found out that a brother and sister committed incest. The public threw them into the water and this time, the deluge subsided. [57] (p. 34; my translation)

The triangle in the middle of Figures 4 and 5 indicates Papak Waqa (scared mountain). Locating Papak Waqa as the coordinate starting point, each curve indicates a river along which Tayal people have built communities and reside. As can see at Figures 4 and 5, each river diffuses from Papak Waqa and brings a Papak Waqa-centric Country into being. However, not every river physically originates from Papak Waqa' (the scared mountain). For instance, those rivers with a cross mark on them do not originate from Papak Waqa (the scared mountain). Moreover, it is clear that Figure 4 is more simplified than Figure 5. The reason is that Teru hesitates to over-generalize the 'name' of rivers in Tayal Country:

When they were naming the rivers, they named it section by section. Because people from downstream could not go over border. You know we have the sense of territory, qes (border). Even though we all belong Tayal people. For example, I am Kanzi clan. I would not go over to Mrqwang clan's territory. If you across the border, then you hmiriq Gaga (against customary law). (Teru from Kanzi people, fieldwork interview on 7 January 2018 at Hêngshan Township)

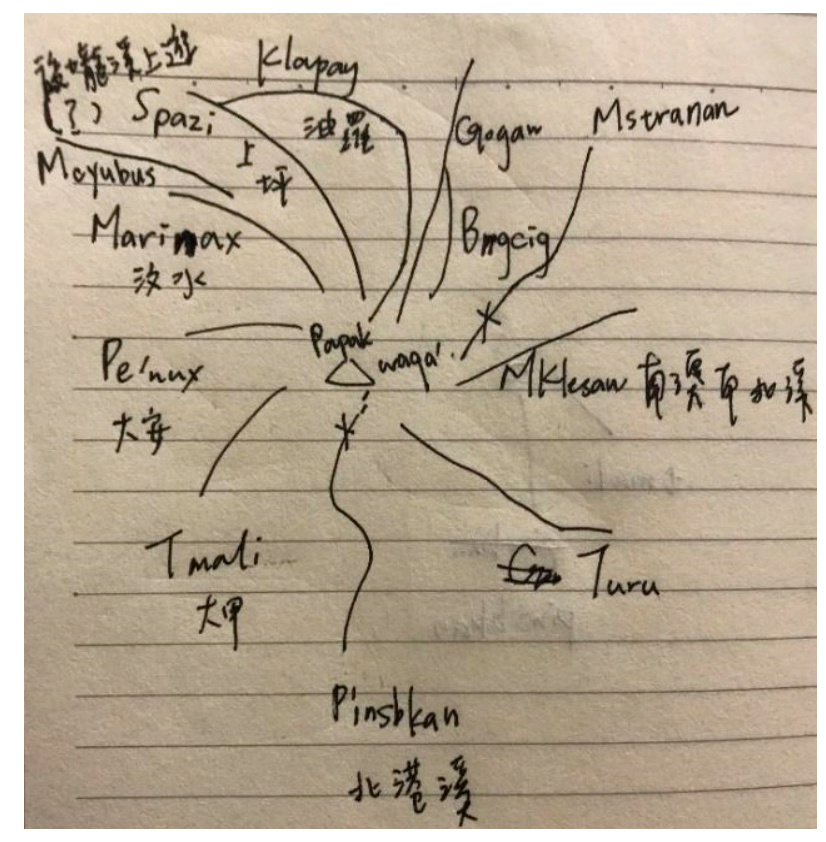

Figure 4. Papak waqa-centric Rivers reproduced by Hsiao.

For Tayal people, the rivers and tributaries provide the pathways by which the ancestors migrated and built a series of settlements (Kuan, 2009: 141). When Pastor Sangus redrew the figure for me (Figure 6), he said:

Tayal society is a society without writing system. Moreover, we do not have the concept of 'ocean'. We do not have 'ocean' in our creation myth. Only mountains and rivers in our creation myth ... For instance, in our creation myth, it was Papak Waqa (the scared mountain) saved our life ... Our migration is about mountains and rivers. We emphasize mountains and rivers ... a very important point is that when speaking of our sense of space, because we do not have writing system, we use myth and lmuhuw (oral history) to deliver (our sense of space). Either we use chanting or description to record our ancestral migration pathway along rivers. (Pastor Sangus, fieldwork interview on 8 January 2018 at Chutung Township) 


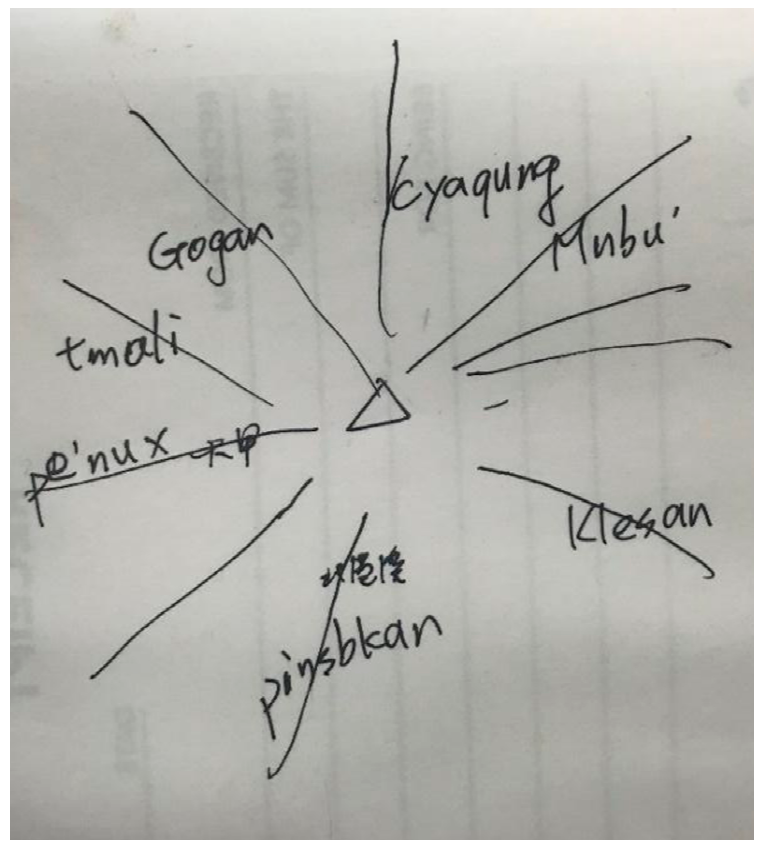

Figure 5. Papak waqa-centric Rivers reproduced by Teru.

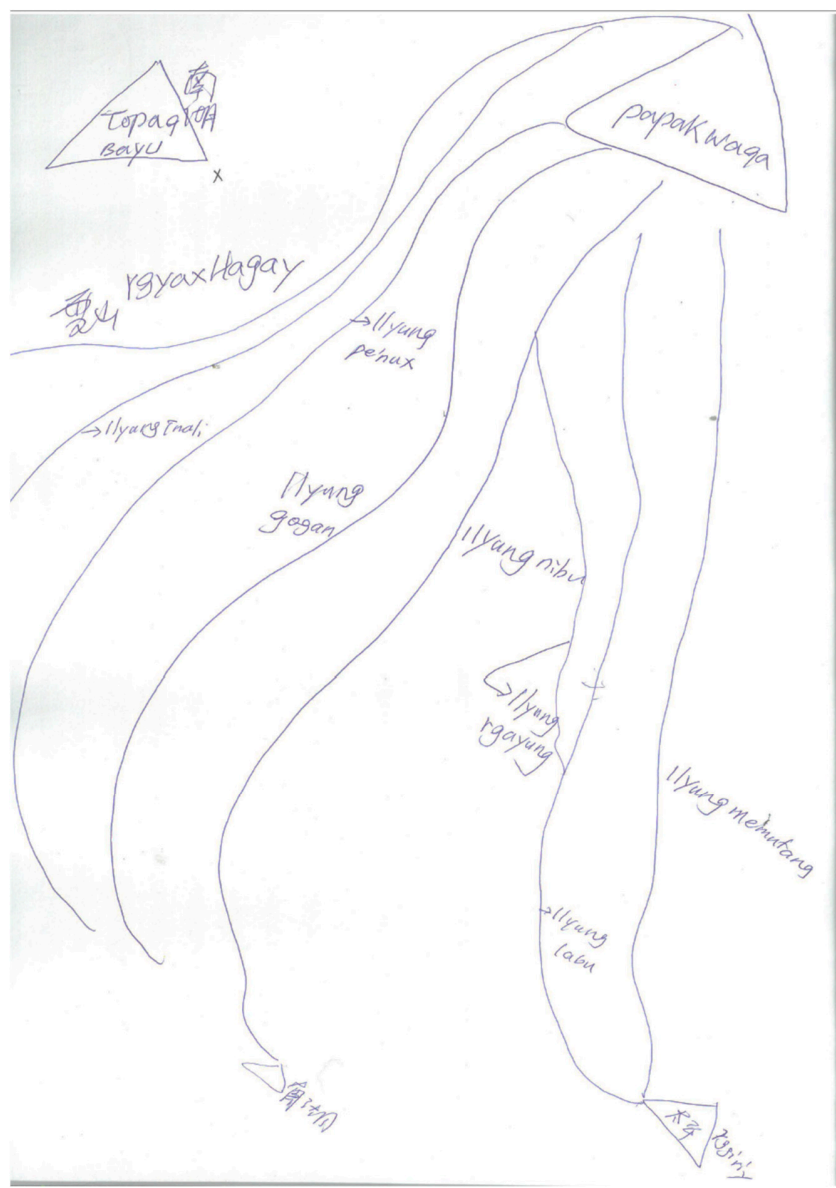

Figure 6. Papak waqa-centric Rivers drawn by Pastor Sangus.

Rivers and mountains are decisive in Tayal ontology. In Tayal language there is a term 'qluw llyung'. Interpreting the term directly, ' $q$ luw' means relatives and 'llyung' means river, so 'qluw llyung' mean 
'relatives along the river'. Through migrations, Tayal people started to settle down and progressively develop settlements within watersheds. Settlements within the same watershed form a military alliance to defend enemies and use the term 'qluw llyung' to refer community members who live within the same watershed. Not only rivers have been used to metaphorize social relations in Tayal society, but also mountains. When proposing a marriage in Tayal society, the groom-to-be is required to give his future brother-in-law 'pintrgyax'. The term 'pintrgyax' comes from the word root 'trgyax', mountain ridge and the term 'trgyax' comes from the word 'rgyax', mountain. 'Pintrgyax', normally is a pig, could be interpreted as the greeting gift the groom-to-be gives to his future brother-in-law when proposing marriage to the bride-to-be's family. Using 'trgyax (mountain ridge)' as the word root implies marriage is merging two families and building relations, just like crossing mountain ridges.

The other thing Pastor Sangus noted is the sense of 'orientation' in Tayal ontology: "Most importantly, other people may believe they came from lowland and migrated to highland. However, for Tayal people, our concept is that we migrate from highland; from mountain" [fieldwork interview on 5 January 2018 at Chutung Township]. Teru also mentioned this feature during her interview:

I used to say to Pastor Sangus that: "our ancestors were really clever. It seems like they saw things from highest point. They saw the world and saw the future. Then they slowly walked down ( ... )." So I said to Pastor Sangus: "Our Tayal people's environment really starts from Papak Waqa (scared mountain) ... when we perceive regions, we perceived it from watersheds instead of administrative districts, such like how many clans dwelled in that watershed. We do not perceive our environment by where can cement roads reach. We perceive our environment by llyung (river). People from same llyung (river) are belong to that llyung (river)". (Teru from Kanzi people, fieldwork interview 2 February 2018 at Tbahu community)

Rivers, mountains and people weave Tayal Country into being and constitute Tayal ontological understandings of beings. For Tayal ontology, every being is connected within a relational web constituted by rivers, mountains and peoples. For me, it is pivotal to establish Tayal ontology when coping with disaster management and climate change as it challenges the predominant paradigm.

\subsection{Reframing Ontologically Pluralist Readings of Situated Resilience}

Recognizing and acknowledging Tayal Country under Pastor Sangus' mentoring completely altered my way of seeing things. It opened up a Tayal-centric perspective as well as a Tayal-centric framing of research. It also facilitates emplacing this paper more powerfully in Tayal Country: as Howitt [36] argues: "Context matters-the historical, geographical, social, and cultural context in which social geographers undertake research fundamentally shapes what we come to know and how we come to represent it to our various audiences" (p. 142). By applying this 'radical contextualist' lens, a Tayal-centric positionality not only acknowledges Tayal people's custodianship to their Country but also shapes a way of doing the research that gives that custodianship primacy in shaping knowledge.

Under conditions of climate change, developing resilient strategies has emerged as a central concern for both academic and public policy discourses. However, as argued by Howitt [32] in this special issue, Indigenous peoples are "easily classified as either dangerously vulnerable or inherently resilient to climate risks" (p. 1 of 16). Such over-simplified images of Indigenous peoples ignore the diverse contexts of Indigenous peoples. Indigenous peoples may share the common experience of being colonized. Yet, the historical, geographical, cultural, social and political contexts of that experience differ from place to place. Thinking that there is a universal or singular solution, a panacea, to global climate challenges to be derived from a universal or singular Indigenous perspective would be an illusion. Rather, the insight to be drawn from Tayal Country is that responding to climate change in the contemporary era requires listening to and on Country. It demands listening attentively to people's stories of connection and belonging. It also demands listening humbly to Country-listening to 
what Country can teach us as a society, rather than assuming a self-privileging-human-centric position or a universalized conclusion relevant regardless of context.

\section{Methodological Principles toward Resilient Tayal Futures}

Three methodological principles are conceptualized from the above discussion to better engage with local knowledge and Indigenous peoples.

1. Decentralize top-down governance

As Australian Aboriginal concept 'Country' has been introduced in this paper, I argue that it is vital to recognize Indigenous peoples' connections to Countries and acknowledge that their custodianship always was and always will be nurturing their Country. To achieve this, it demands that researchers and government agencies rethink privileged top-down governance mentality. A top-down governance system favors universal and generalized solution for a resilient future and rejects contextualizing environmental issues in a specific-temporal-and-spatial scale and cultural-and-geographical-appropriate context. It projects a singular imagination of a resilient future. However, paying attention to local impact and listening to local responses will situate the notion and practice of resilience in a context. As I mentioned in Section One, the concept of 'situated resilience' provokes a radical recognition of place, where the knowledge is generated, maintained and practiced. It is the importance of place in knowledge systems making the impossibility of having a universally applicable climate change strategy. Acknowledging Indigenous peoples' custodianship and hearing local stories of connections will enlighten a very different pathway toward resilient governance.

\section{Deauthorize expert-centric narrative}

It is important to rethink how Indigenous peoples' knowledge and custodianship of their Countries have been omitted, marginalized and deauthorized by settler states' discursive constructions. In the Tayal people's context, their custodianship of Country has been ignored and their knowledge of their Country has been overlooked. It is critical for settler states and Western-science-trained experts to treat, think and view Indigenous peoples as intellectually equivalent partners, not as subordinate subjects or innocent victims. Sharing and valuing cross-cultural knowledge to each other does not devalue one or both. On the contrary, it demonstrates a great reciprocity that would bridge different knowledge systems. Only by justly valuing all stakeholders' knowledge can the partnership be bonded and the mutual trust can be built. To mitigate climate change and manage natural disaster, sharing cross-cultural knowledge will not solely enrich different knowledge systems' understanding to each other. More importantly, it will provide a strong sense of sharing obligation to all stakeholders as their knowledge are equally weighted.

\section{Decolonize taken-for-granted ontological understanding}

Nature is never natural. The constructed dichotomy of 'nature/culture' has been subjected to critical examinations across disciplines (for instance, see [58-62]). Drawing from the Tayal experience, I maintain that in Tayal ontology, nature is never separated from human society. In Tayal ontology, nature, the mountains and rivers, is not only the environment on which their livelihoods depend. It is their identity, their sense of belonging and their Country. For Tayal people, environmental issues, including climate change and natural disasters, are not separate events from their culture. It is their Country. Tayal ways of seeing, thinking and doing are fundamentally built on and shaped by their mountains and rivers. Mountains and rivers are not just non-human agencies for Tayal people. It is a significant agency in their more-than-human ontology. To achieve resilience environmental governance, it is necessary to recognize and respect ontology pluralism in the contested cultural landscape, a lesson not only for the Taiwanese government, but also for other settlers' states. 


\section{Conclusions}

Three key notions mobilize this paper: Country, ontological pluralism and situated resilience. This paper starts with how acknowledging Tayal Country would shift the taken-for-granted research paradigm of resilience study. Then this paper argues that it is pivotal to recognize ontological pluralism in contested cultural landscapes, such as Taiwan. It deprivileges a conventional framework that deems resilience strategy to be universally applicable. This paper demands a careful rethinking and argues that resilience strategies, on the contrary, are embedded in a specific-temporal-and-spatial scale and cultural-and-geographical-appropriate context. Developing methodological principles to listen to and learn from local resilience requires immersing researchers in the local context. This paper draws from my own experience of working with Tayal mentors. Through in-depth and long-term fieldwork, I came to understand that for Tayal people, stories of connection, place and belonging and lmuhuw (migration history chanting) all play critical roles in their more-than-human ontology. Tayal people's custodianship of their Country is persistent and resistant despite colonial interventions. There is no way to truly understand Tayal resilience without acknowledging their custodianship of Country. In order to achieve so, it is critical to develop methodological principles. Three methodological principles were abstracted from my own experience of working with Tayal people: (1) Decentralize top-down governance; (2) Deauthorize expert-centric narrative; (3) Decolonize taken-for-granted ontological understanding.

As mentioned earlier, the insight to be drawn from Tayal Country is that responding to climate change in the contemporary era requires listening to and on Country. Implementing existing methodology on Indigenous peoples would be duplicating the settler-sanctioned research paradigm, which has been forcibly imposed on Indigenous peoples during colonial/imperial periods. The three methodological principles developed in this paper are hoping to provide a guidance for interested researchers and practitioners to ethically engage Indigenous resilience. In the Taiwanese settings, I argue that understanding the value of local governance, seeing Indigenous peoples as research partners rather than subordinated participants and learning to recognize the ontological politics of resilience are critical to achieving resilient Tayal futures.

However, the three methodological principles are not the panacea to the global climate crisis. I have emphasized in Section Three that Indigenous people are not a homogenous group, nor are they a conflated imagination that served as the opposite categorization against 'settler'. Indigenous peoples' cultures are diverse. It is important to acknowledge the multiplicity and complexity of connections. This paper conceptualizes and argues three methodological principles that I have learnt from ethical engagements with my Tayal informants. I hope these three principles can be utilized as a foundation for framing resilience science research in the Anthropocene. Engaging culturally diverse Indigenous groups to climate change adaptation is never easy. It involves careful listening to the Indigenous people, their connections to their Countries. It also involves fundamental de-learning on taken-for-granted understanding for disaster and climate. It requires a humble and respectful re-learning on what Indigenous people can offer to us, not solely as small communities but also as a whole human society. It needs determination to take actions to be responsible for ethical engagement. It is requisite to have a deep commitment on framing resilience science in not only centered on ethical engagements but also to frame studies in the ethical way. This requires an attentive rethinking on framing the Indigenous research participants not just as objects, but as active audience for the research itself.

Before concluding this paper, I would like to acknowledge Tayal Country. Tayal people and their Country have profoundly taught me a different way to view the world. People are not disconnected from the environment in Tayal ontology. On the contrary, rivers, mountains and people co-weave into existence in Tayal Country. This concept of weaving into existence is such a prominent component in Tayal philosophy and ontology. It is pivotal to adopt the culturally appropriate methodological principles in order to provide resilience plans for Tayal people when it comes to climate change. This will open up the possibility to improve Taiwanese government's responses to both Indigenous 
rights and climate change in the Anthropocene by acknowledging Tayal people's custodianship to their Country, and it will also offer more resilient futures to Tayal people and the Taiwanese society.

Funding: This research is supported by Higher Degree Research Funding from the Department of Geography and Planning, Macquarie University (the sponsored: Yi-Shiuan Chen; Macquarie University Ethics Approval No 5201600433).

Acknowledgments: I would like to acknowledge Tayal participants and their families involved in this research. I acknowledge Tayal custodianship and caring that nurtured, and continue to nurture Tayal Country. We also acknowledge the use of Linda Tuhiwai Smith's words in our title from her 1999 book: Decolonizing methodologies: Research and indigenous peoples.

Conflicts of Interest: The authors declare no conflict of interest.

\section{Appendix A}

Table A1. Interviewees for In-depth interviews.

\begin{tabular}{|c|c|c|c|c|c|c|c|}
\hline $\begin{array}{c}\text { Name } \\
\text { (Pseudonym) }\end{array}$ & $\begin{array}{c}\text { Interviews } \\
\text { Date }\end{array}$ & Gender & Occupation & Age & $\begin{array}{l}\text { Ethnic } \\
\text { Group }\end{array}$ & $\begin{array}{c}\text { Rationale of } \\
\text { Selection }\end{array}$ & Interview Themes \\
\hline Sangus & $\begin{array}{c}2018.1 .5 \\
2018.1 .8 \\
2018.1 .31\end{array}$ & Male & $\begin{array}{l}\text { Retired } \\
\text { minister }\end{array}$ & $60 \sim$ & Tayal & $\begin{array}{l}\text { Sangus is a retired } \\
\text { minister of the } \\
\text { Presbyterian Church. } \\
\text { He has participated in } \\
\text { the Indigenous social } \\
\text { movements since } \\
\text { 1990s. He is devoted } \\
\text { to Tayal cultural } \\
\text { preservation, } \\
\text { revitalization and } \\
\text { promotion. He has } \\
\text { expertise in Tayal } \\
\text { customary chanting, a } \\
\text { form of oral history } \\
\text { recording Tayal } \\
\text { people's migration. }\end{array}$ & $\begin{array}{l}\text { - } \quad \text { Mapping of Tayal } \\
\text { traditional territory } \\
\text { - Tayal history } \\
\text { and culture } \\
\text { - } \quad \text { Indigenous polity } \\
\text { and identity }\end{array}$ \\
\hline Teru & $\begin{array}{l}2018.1 .7 \\
2018.2 .2\end{array}$ & Female & $\begin{array}{c}\text { Cultural } \\
\text { worker } \\
\text { and farmer }\end{array}$ & $50 \sim$ & Tayal & $\begin{array}{l}\text { Teru is a dedicated } \\
\text { cultural worker. She } \\
\text { applies government } \\
\text { projects to work on } \\
\text { Tayal culture } \\
\text { preservation, } \\
\text { revitalization and } \\
\text { promotion. She also } \\
\text { grows customary } \\
\text { crops and commercial } \\
\text { crops. }\end{array}$ & $\begin{array}{l}\text { - } \quad \text { Mapping of Tayal } \\
\text { traditional territory } \\
\text { Tayal history } \\
\text { and culture } \\
\text { - } \quad \text { Experience of } \\
\text { running a Tayal } \\
\text { local business }\end{array}$ \\
\hline
\end{tabular}

\section{References}

1. Hosen, N.; Nakamura, H.; Hamzah, A. Adaptation to Climate Change: Does Traditional Ecological Knowledge Hold the Key? Sustainability 2020, 12, 676.

2. Yang, H.; Ranjitkar, S.; Zhai, D.; Zhong, M.; Goldberg, S.D.; Salim, M.A.; Wang, Z.; Jiang, Y.; Xu, J. Role of Traditional Ecological Knowledge and Seasonal Calendars in the Context of Climate Change: A Case Study from China. Sustainability 2019, 11, 3243.

3. Chunhabunyatip, P.; Sasaki, N.; Grünbühel, C.; Kuwornu, J.K.; Tsusaka, T.W. Influence of indigenous spiritual beliefs on natural resource management and ecological conservation in Thailand. Sustainability 2018, 10, 2842.

4. Smith, L.T. Decolonizing Methodologies: Research and Indigenous Peoples, 2nd ed.; University of Otago Press: Dunedin, New Zealand; Zed Books: London, UK, 2012. 
5. Howitt, R.; Doohan, K.; Suchet-Pearson, S.; Lunkapis, G.J.; Muller, S.; Lawrence, R.; Prout, S.; Veland, S.; Cross, S. Capacity Deficits at Cultural Interfaces of Land and Sea Governance. In Reclaiming Indigenous Planning; Walker, R., Jojola, T.S., Natcher, D.C., Eds.; McGill-Queens University Press: Montreal, QC, Canada; Kingston, ON, Canada, 2013; pp. 313-338.

6. Council of Indigenous Peoples. Indigenous Population Statistics. Available online: https://www.cip. gov.tw/portal/docDetail.html?CID=940F9579765AC6A0\&DID=2D9680BFECBE80B6E7AE3875129EF341 (accessed on 12 August 2020)(Mandarin version available only).

7. Chen, Y.-S.; Suchet-Pearson, S.; Howitt, R. Reframing Indigenous water rights in 'modern' Taiwan: Reflecting on Tayal experience of colonized common property. Int. J. Commons 2018, 12, 378-401.

8. Wright, S.S.-P.S.; Lloyd, K.; Burarrwanga, L.; Ganambarr, R.; Ganambarr-Stubbs, M.; Ganambarr, B.; Maymuru, D. The politics of ontology and ontological politics. Dialogues Hum. Geogr. 2016, 6, $23-27$. [CrossRef]

9. Hsu, M.; Howitt, R.; Chi, C.C. The idea of 'Country': Reframing post-disaster recovery in Indigenous Taiwan settings. Asia Pac. Viewp. 2014, 55, 370-380.

10. Rose, D.B. Nourishing Terrains: Australian Aboriginal Views of Landscape and Wilderness; Australian Heritage Commission: Canberra, Australian, 1996.

11. Country, B.; Wright, S.; Suchet-Pearson, S.; Lloyd, K.; Burarrwanga, L.; Ganambarr, R.; Ganambarr-Stubbs, M.; Ganambarr, B.; Maymuru, D. Working with and learning from Country: Decentring human author-ity. Cult. Geogr. 2014. [CrossRef]

12. Honderich, T. (Ed.) The Oxford Companion to Philosophy New Edition; Oxford University Press: New York, NY, USA, 2005.

13. Bullock, A.; Stallybrass, O.; Trombley, S. (Eds.) The Fontana Dictionary of Modern Thought, 2nd ed.; Fontana Press: Lodon, UK, 1988.

14. Howitt, R.; Suchet-Pearson, S. Ontological Pluralism in Contested Cultural Landscapes. In Handbook of Cultural Geography; Anderson, K., Domosh, M., Pile, S., Thrift, N., Eds.; Sage: London, UK, 2003; pp. 557-569.

15. Howitt, R.; Suchet-Pearson, S. Rethinking the Building Blocks: Ontological Pluralism and the Idea of 'Management'. Geogr. Ann. Ser. B Hum. Geogr. 2006, 88, 323-335.

16. Country, B.; Suchet-Pearson, S.; Wright, S.; Lloyd, K.; Burarrwanga, L. Caring as Country: Towards an ontology of co-becoming in natural resource management. Asia Pac. Viewp. 2013, 54, 185-197.

17. Cameron, E.; de Leeuw, S.; Desbiens, C. Indigeneity and ontology. Cult. Geogr. 2014, 21, 19-26. [CrossRef]

18. Theriault, N. A forest of dreams: Ontological multiplicity and the fantasies of environmental government in the Philippines. Political Geogr. 2017, 58, 114-127. [CrossRef]

19. Lloyd, K.W.S.; Suchet-Pearson, S.; Burarrwanga, L.; Country, B. Reframing Development through Collaboration: Towards a relational ontology of connection in Bawaka, North East Arnhem Land. Third World Q. 2012, 33, 1075-1094.

20. Akter, S.; Mallick, B. The poverty-vulnerability-resilience nexus: Evidence from Bangladesh. Ecol. Econ. 2013, 96, 114-124. [CrossRef]

21. Berkes, F. Understanding uncertainty and reducing vulnerability: Lessons from resilience thinking. Nat. Hazards 2007, 41, 283-295.

22. Folke, C. Resilience: The emergence of a perspective for social-ecological systems analyses. Glob. Environ. Chang. 2006, 16, 253-267. [CrossRef]

23. Gaillard, J.C. Vulnerability, capacity and resilience: Perspectives for climate and development policy. J. Int. Dev. 2010, 22, 218-232. [CrossRef]

24. Haque, C.E.; Etkin, D. People and community as constituent parts of hazards: The significance of societal dimensions in hazards analysis. Nat. Hazards 2007, 41, 271-282.

25. Miller, F.; Osbahr, H.; Boyd, E.; Thomalla, F.; Bharwan, S.; Ziervogel, G.; Walker, B.; Birkmann, J.; Leeuw, S.V.d.; Rockström, J.; et al. Resilience and Vulnerability: Complementary or Conflicting Concepts? Ecol. Soc. 2010, 15, 11. Available online: http://www.ecologyandsociety.org/vol15/iss13/art11/ (accessed on 12 August 2020).

26. Berkes, F.; Ross, H. Community Resilience: Toward an Integrated Approach. Soc. Nat. Resour. 2013, 26, 5-20. [CrossRef] 
27. Country, B.; Wright, S.; Suchet-Pearson, S.; Lloyd, K.; Burarrwanga, L.; Ganambarr, R.; Ganambarr-Stubbs, M.; Ganambarr, B.; Maymuru, D.; Sweeney, J. Co-becoming Bawaka: Towards a relational understanding of place/space. Prog. Hum. Geogr. 2015, 40, 455-475. [CrossRef]

28. Simon, S.; Randalls, S. Geography, ontological politics and the resilient future. Dialogues Hum. Geogr. 2016, 6, 3-18. [CrossRef]

29. Fisher, K. Coordinating and situating resilience multiple. Dialogues Hum. Geogr. 2016, 6, 32-36. [CrossRef]

30. Wright, S.; Suchet-Pearson, S.; Lloyd, K.; Burarrwanga, L.; Ganambarr, R.; Ganambarr-Stubbs, M.; Ganambarr, B.; Maymuru, D. Gathering of the clouds: Attending to indigenous understandings of time and climate through songspirals. Geoforum 2020, 108, 295-304.

31. Berkes, F.; Ross, H. Panarchy and community resilience: Sustainability science and policy implications. Environ. Sci. Policy 2016, 61, 185-193.

32. Howitt, R. Decolonizing People, Place and Country: Nurturing Resilience across Time and Space. Sustainability 2020, 12, 5882.

33. Langton, M. Welcome to Country: A Travel Guide to Indigenous Australia; Hardie Grant Publishing: Melbourne, Australia, 2018.

34. Merlan, F. Recent rituals of Indigenous recognition in Australia: Welcome to country. Am. Anthropol. 2014, 116, 296-309.

35. Howitt, R.; Lendrum, M.; Russo, S.; Seymour, L.; Smith, R.; Wergeltoft, N. Being-Together-on-country: Reframing sustainability planning in remote communities in the Northern Territory. In Proceedings of the Institute of Australian Geographers, Melbourne, Australia, 2-4 July 2007; University of Melbourne: Melbourne, Australia, 2007.

36. Howitt, R. Knowing/Doing. In A Companion to Social Geography; Del Casino, V.J., Jr., Thomas, M.E., Cloke, P., Panelli, R., Eds.; Wiley-Blackwell: Chichester, UK, 2011; pp. 131-145.

37. Chen, Y.-S.Y.; Kuan, D.-W.; Suchet-Pearson, S.; Howitt, R. Decolonizing property in Taiwan: Challenging hegemonic constructions of property. Environ. Plan. D Soc. Space 2018, 36, 987-1006. [CrossRef]

38. Fang, W.-T.; Hu, H.-W.; Lee, C.-S. Atayal's identification of sustainability: Traditional ecological knowledge and indigenous science of a hunting culture. Sustain. Sci. 2016, 11, 33-43. [CrossRef]

39. Kuan, D.-W. A River Runs Through It: Story of Resource Management, Place Identity and Indigenous Knowledge in Marqwang, Taiwan; University of Hawai'i at Manoa: Honolulu, HI, USA, 2009.

40. Chen, Y.-S. Tayal Time, Space and Territory: Rethinking Scale, Property and Taiwan. Ph.D. Thesis, Macquarie University, Sydney, Australia, 2018.

41. Hsu, M. Expert-Centred Discourses and Indigenous Autonomy in Post-Disaster Settings: Insights from Wutai Rukai Experiences in Taiwan; Macquarie University: Sydney, Australia, 2016.

42. Chang, Y.-T.E. Rethinking Indigenous Pathways to Health in Eastern Taiwan: Negotiating the Complex Terrains of Local Sociality, Cultural Sovereignty, and Biomedical Governmentality. Ph.D. Thesis, Macquarie University, Sydney, Australia, 2020.

43. Sikes, P. Decolonizing research and methodologies: Indigenous peoples and cross-cultural contexts. Pedagog. Cult. Soc. 2006, 14, 349-358.

44. Mlcek, S. Decolonizing methodologies to counter 'minority' spaces. Continuum 2017, 31, 84-92. [CrossRef]

45. Leslie, L. Dhiiyaan Ngay Kamilaroi, Winangaldanha Ngaya Nginaaynya (My Kamilaroi Family, I Hear You): Physical Activity, Ageing and the Places of Freedom in a Kamilaroi Family; Macquarie University: Sydney, Australia, 2014.

46. Zheng, G.B. Discussing the The Construction of Contemporary "Tayal" Historical Memory from Ancestral Controversies; National Chengchi University: Taipei, Taiwan, 2006; (Mandarin version available only).

47. Lin, Y.R. Ecological Governance of Indigenous Peoples' Land: The Case Study of Nan-shan Event. J. Taiwan Indig. Stud. Assoc. 2015, 5, 59-70. (Mandarin version available only)

48. Lin, Y.R. Lessons from the Tayal's Traditional Territory and Their River Basin Governance. Taiwan A Radic. Q. in Soc. Stud. 2015, 100, 291-310. (Mandarin version available only)

49. Palmer, M. Sustaining indigenous geographies through world heritage: A study of Uluru-Kata Tjuta National Park. Sustain. Sci. 2016, 11, 13-24. [CrossRef]

50. Coombes, B. Indigenism, Public Intellectuals, and the Forever Opposed-Or, the Makings of a "Hori Academic". In Indigenous Pathways into Social Research: Voices of a New Generation; Donna, M.M., Fiona, C., Bagele, C., Eds.; Routledge: New York, NY, USA, 2016; pp. 71-88. 
51. Barnd, N. Inhabiting Indianness: US Colonialism and Indigenous Geographies; ProQuest Dissertations Publishing: Ann Arbor, MI, USA; Uneversity of California: San Diego, CA, USA, 2008.

52. Coombes, B.; Gombay, N.; Johnson, J.T.; Shaw, W.S. The Challenges of and from Indigenous Geographies. In $A$ Companion to Social Geography; Del Casino, V.J., Jr., Thomas, M.E., Cloke, P., Panelli, R., Eds.; Wiley-Blackwell: Oxford, MS, USA, 2011; pp. 471-489.

53. Frantz, K.; Howitt, R. Geography for and with indigenous peoples: Indigenous geographies as challenge and invitation. GeoJournal 2012, 77, 727-731. [CrossRef]

54. Johnson, J.T.; Larsen, S.C. Being Together in Place: Indigenous Coexistence in a More Than Human World; University of Minnesota Press: Minneapolis, MN, USA, 2017.

55. Hsiao, S.H. Rgrgyax Hlahuy-Decolonizing Forested Mountains: Tayal People's Spatial Reconstruction under the Vision of Mt. Papak Waqa; National Taiwan Normal University: Taipei, Taiwan, 2016.

56. Utsurikawa, N.; Mabuchi, T.; Miyamoto, N. The Formosan Native Tribes: A Genealogical and Classificatory Study; Council of Aboriginal Affairs, the Executive Yuan: Taipei, Taiwan, 2011; (Mandarin version available only).

57. Provisional Commission for the Investigation if Taiwanese Old Customs. Indigenous Peoples' Custom Investigation Report No. 5 Tayal People v. 1; Institute of Ethnology, Academia Sinica: Taipei, Taiwan, 2012; (Mandarin version available only).

58. Latour, B. Politics of nature: How to Bring the Sciences into Democracy; Harvard University Press: Cambridge, MA, USA, 2004.

59. Whatmore, S. Hybrid Geographies: Natures Cultures Spaces; Sage: London, UK; Thousand Oaks, UK, 2002.

60. Haraway, D. Simians, Cyborgs, and Women: The Reinvention of Nature; Routledge: New York, NY, USA, 2013.

61. Braun, B.; Castree, N. Remaking Reality: Nature at the Millenium; Routledge: London, UK, 2005.

62. Castree, N.; Braun, B. Social Nature: Theory, Practice, and Politics; Wiley-Blackwell: Malden, MA, USA; Oxford, MS, USA, 2001.

Publisher's Note: MDPI stays neutral with regard to jurisdictional claims in published maps and institutional affiliations.

(C) 2020 by the author. Licensee MDPI, Basel, Switzerland. This article is an open access article distributed under the terms and conditions of the Creative Commons Attribution (CC BY) license (http://creativecommons.org/licenses/by/4.0/). 